\title{
Urgensi Komunikasi Interpersonal Dalam Al-Qur'an Sebagai Pustakawan
}

\section{(Urgency of Interpersonal Communication in Al-Qur'an as Librarian)}

\author{
Muhamad Bisri Mustofa ${ }^{1 凶}$, Siti Wuryan ${ }^{2}$, Rosidi $^{3}$ \\ ${ }^{1}$ Program Studi Ilmu Perpustakaan dan Informasi Islam, UIN Raden Intan Lampung, Indonesia \\ 2 Program Studi Komunikasi dan Penyiaran Islam, UIN Raden Intan Lampung, Indonesia \\ 3 Program Studi Bimbingan dan Konseling Islam, UIN Raden Intan Lampung, Indonesia

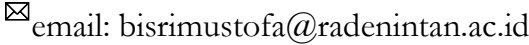

\begin{tabular}{ccc}
\hline First received: & Revised: & Final Accepted: \\
13 October 2020 & 18 November 2020 & 30 December 2020 \\
\hline
\end{tabular}

\begin{abstract}
The development of scientific communication and Islam has an effect on the view of communication in general and on Islamic concepts, including interpersonal communication or also known as interpersonal communication which has a relationship in the field of Islamic communication, in terms of various aspects among them in the relationship between bumans. Al-Qur'an mentions various meanings related to relationships between human beings, in this case referred to as interpersonal communication, namely the concept of Qaulan Sadidan, Qaulan Maysura, Qaulan Layyinan, Qaulan Kariman, Qaulan Ma'rufa and Qaulan Baligha. In this connection, the writer will discuss more about the urgency of interpersonal communication in the framework of Islamic communication towards librarians, as a library manager who has interpersonal communication skills. This research is a library research in various literature such as journals, books and others. Literature review method, which examines the concept of interpersonal communication from research books and journals. The data from the results of this study were analyzed qualitatively, meaning that the library data were analyzed in depth, holistically, and comprehensively with content analysis techniques. In terms of interpersonal communication theories in the perspective of Islamic communication, it focuses more on the process of delivering messages or information from librarians, using communication principles and principles based on the Koran and Hadith. The process of conveying messages to audiences directly or through the media upholding the truth taught by religion is collaborated in the form of the service of a librarian. In this process, a librarian can apply more forms of interpersonal communication to readers based on the Al-Qur'an.
\end{abstract}

Keywords : Interpersonal Communication; Islamic Communication; Librarian.

\begin{abstract}
ABSTRAK
Perkembangan dari keilmuan komunikasi dan keislaman berefek kepada pandangan komunikasi secara umum dan kepada konsep-konsep keislaman, diantaranya Komunikasi interpersonal atau disebut juga komunikasi antar pribadi memiliki keterkaitan dalam bidang komuinkasi islam, di tinjau dari berbagai aspek diantara nya pada hubungan antar sesama manusia. Al-Qur'an menyebutkan berbagai makna terkait hubungan antara sesama manusia dalam hal ini disebut sebagai komunikasi interpersonal yaitu konsep Qaulan Sadidan, Qaulan Maysura, Qaulan Layyinan, Qaulan Kariman, Qaulan Ma'rufa dan Qaulan Baligha. Kaitan dengan hal ini penulis akan membahas lebih lanjut tentang urgensi komunikasi interpersonal dalam bingkai komunikasi islam terhadap pustakawan, sebagai seorang pengelola perpustakaan yang memiliki kemampuan komunikasi interpersonal. Penelitian ini merupakan penelitian pustaka yang di berbagai leteratur seperti jurnal, buku dan lain-lain. Metode literature reviu, yaitu mengkaji konsep komunikasi interpersonal dari buku dan jurnal hasil penelitian. Data dari hasil penelitian ini dianalisa secara kualitatif, artinya data kepustakaan dianalisis secara mendalam, holistik, dan komprehensif dengan teknik analisis content. Ditinjau dari teori-teori komunikasi interpersonal dalam perspektif komunikasi Islam, lebih fokuskan kepada proses penyampaian pesan atau informasi dari pustakawan, dengan menggunakan kaedah dan prinsip komunikasi yang berdasarkan kepada Alquran dan Hadis. Proses penyampaian pesan kepada audien secara langsung atau melalui media menjunjung kebenaran yang diajarkan oleh agama dikolaborasikan dalam bentuk pelayanan seorang pustakawan.
\end{abstract}


Dalam proses ini seorang pustakwan dapat lebih menerapkan bentuk komunikasi interpersonal kepada para pembaca dengan berlandaskan kepada Al-Qur'an.

Kata kunci : Komunikasi Interpersonal; Komunikasi Islam; Pustakawan.

\section{PENDAHULUAN}

Kegiatan komunikasi interpersonal merupakan kegiatan sehari-hari yang paling banyak dilakukan oleh manusia sebagai makhluk sosial. Sehingga kemampuan berkomunikasi merupakan suatu kemampuan yang paling mendasar (Fadlan, 2019). Komunikasi interpersonal telah melingkupi aspek kehidupan yang luas dan dapat meluas jangkauannya. Komunikasi interpersonal dapat mencakup semua jenis hubungan manusia mulai dari hubungan yang paling singkat, sederhana dan biasa, yang seringkali diwarnai oleh kesan pertama, hingga hubungan yang paling mendalam dan relatif permanen. Komunikasi interpersonal merupakan suatu proses penyampaian pesan dari seseorang kepada orang lain atau pihak lain. Menurut pemahaman seperti ini, komunikasi dikaitkan dengan pertukaran informasi yang bermakna dan harus membawa hasil di antara orang-orang yang berkomunikasi. Komunikasi interpersonal menghendaki informasi atau pesan dapat tersampaikan dan hubungan di antara orang yang berkomunikasi dapat terjalin. Oleh karena itu setiap orang apapun tujuan mereka, dituntut memiliki keterampilan komunikasi interpersonal agar mereka bisa berbagi informasi, bergaul dan menjalin kerjasama untuk bisa bertahan hidup.

Perpustakaan sebagai pusat sumber informasi, di dalamnya terdapat beberapa komponen yaitu sebuah gedung, koleksi, pengolahan, layanan, pemustaka, sarana dan prasarana, serta untuk menjalankan semua aktivitas perpustakaan tidak lepas dari pengelolanya yaitu pustakawan. Undang-Undang Nomor 43 Tahun 2007 mendefinisikan pustakawan sebagai seseorang yang memiliki kompetensi yang diperoleh melalui pendidikan dan/atau pelatihan kepustakawanan serta mempunyai tugas dan tanggung jawab untuk melaksanakan pengelolaan dan pelayanan perpustakaan.3 Sementara itu, menurut Peraturan Menteri Pendayagunaan Aparatur Negara dan Reformasi Birokrasi Nomor 9 Tahun 2014 bahwa pustakawan adalah Pegawai Negeri Sipil (PNS) yang diberi tugas, tanggung jawab, wewenang, dan hak untuk melaksanakan kegiatan kepustakawanan. Pustakawan sebagai seorang komunikator di sebuah perpustakaan dapat menggunakan komunikasi interpersonal dalam bingkai Al-Qur'an, dan di implementasikan dalam perkataan sesuai dengan petunjuk Al-Qur'an yaitu : Qaulan Sadidan, Qaulan Maysura, Qaulan Layyinan, Qaulan Kariman, Qaulan Ma'rufa and Qaulan Baligha. Lebih penting lagi ketika aktivitas di dalam lingkungan pekerjaan pustakawan dimana sebagian besar kegiatannya merupakan kegiatan komunikasi interpersonal dimulai dari interaksi dengan para pembaca. Oleh sebab itu, kemampuan atau soft skill komunikasi interpersonal yang berandaskan dengan AlQur'an sangatlah penting.

\section{METODE PENELITIAN}

Penelitian ini merupakan penelitian pustaka yang di berbagai leteratur seperti jurnal, buku dan lain-lain. Metode literature review, yaitu mengkaji konsep komunikasi interpersonal dari buku dan jurnal hasil penelitian. Data dari hasil penelitian ini dianalisa secara kualitatif, artinya data kepustakaan dianalisis secara mendalam, holistik, dan komprehensif dengan teknik analisis content.

\section{HASIL PENELITIAN DAN PEMBAHASAN}

\section{Pengertian Komunikasi Interpersonal}

Komunikasi Interpersonal (interpersonal communication) didefenisikan oleh Joseph A. Devito dalam bukunya "The Interpersonal Communication Book". "The process of sending and receiving messages between two persons, or among a small group of persons, with some effect and some immediate feedback." (Devito, 
1989: 4) "Proses pengiriman dan penerimaan pesan-pesan antara dua orang atau di antara sekelompok kecil orang-orang, dengan beberapa efek dan beberapa umpan balik seketika".

Komunikasi Interpersonal dapat berlangsung antara dua orang yang memang sedang berdua-duaan seperti suami istri yang sedang bercakap-cakap, atau antara dua orang dalam suatu pertemuan, misalnya antara penyaji makalah dengan salah seorang peserta suatu seminar (Effendy, 2003: 60).

Komunikasi Interpersonal adalah sangat penting dikarenakan komunikasi Interpersonal melibatkan personalnya antara dua orang atau lebih secara langsung yaitu dengan tatap muka. seperti yang dikatakan oleh R. Wayne Pace dalam Haffied Cangara bahwa "Interpersonal communication is communication involving two or more people in a face setting” (Cangara, 2008: 32). Selain itu Onong Uchjana Effendi mengemukakan komunikasi Interpersonal dianggap paling ampuh dalam upaya mengubah sikap, kepercayaan, opini, dan perilaku komunikan (Effendy, 2003:62).

Dari beberapa pendapat di atas dapat diketahui bahwa komunikasi Interpersonal berlangsung secara tatap muka (face to face) maka terjadilah kontak pribadi (personal contact), sehingga hasil umpan balik berlangsung seketika, sehingga komunikator dapat mengetahui apakah komunikasinya ditanggapi positif atau negatif oleh komunikan dan hasil ini dapat dilihat dari mimik atau ekspresi wajah, jika tanggapan komunikan itu negatif maka dapat diubah gaya komunikasi tersebut. Namun saat ini dengan perkembangan teknologi yang semakin maju memberi kemudahan dalam melakukan komunikasi Interpersonal, terkadang bertatap muka langsung (face to face) itu tidak harus bertemu secara langsung, karena dengan adanya media komunikasi sehingga dikatakan bahwa dunia itu dalam genggaman itu terjadi. Media komunikasi yang digunakan seperti telephone, handphone, teleconference, internet, dan sebagainya. Bahkan untuk handphone saat sekarang ini yang sudah mempunyai fasilitas 4G, sudah dapat bertatap muka di depan layar secara langsung, begitu juga dengan internet dan teleconference.

Pendapat lain mengatakan bahwa komunikasi Interpersonal merupakan proses pengiriman dan penerimaan pesan di antara dua orang atau di antara sekelompok kecil orang, dengan berbagai efek dan umpan balik (feed back) (Widjaya, 2000: 122). Pendapat lain seperti Mulyana mengatakan, pemahaman tentang komunikasi bertatap muka langsung harus diawali dengan pembentukan konsep diri. Bahwa konsep diri yaitu pandangan kita mengenai siapa diri kita, dan itu dapat diperoleh lewat informasi yang diberikan orang lain kepada kita. Konsep diri paling dini pada umumnya dipengaruhi oleh keluarga dan orang-orang yang dekat lainnya di sekitar kita. Mereka itulah disebut dengan significant other. Orang tua kita atau siapapun yang pertama kali memelihara kita, mereka itulah yang pertama kali mengetahui bagaimana kita. Oleh karena itu, Mulyana mengatakan bahwasanya manusia itu tidak pernah berkomunikasi dengan manusia lainnya mereka tidak sadar bagaimana diri mereka sebenarnya dan kesadaran itu didapatkan dari suatu proses komunikasi yang disebut komunikasi Interpersonal (Widjaya, 2001: 7-8).

Sedangkan menurut Arni Muhammad mengatakan bahwa Komunikasi Interpersonal adalah proses pertukaran informasi diantara seseorang dengan paling kurang seorang lainnya atau biasanya di antara dua orang yang dapat langsung diketahui balikannya. Dengan bertambahnya orang yang terlibat dalam komunikasi, menjadi bertambahlah persepsi orang dalam kejadian komunikasi sehingga bertambahlah komplekslah komunikasi tersebut. Komunikasi Interpersonal adalah membentuk hubungan dengan orang lain (Muhammad, 2002: 159).

Dari beberapa definisi di atas dapat diambil kesimpulan bahwa komunikasi Interpersonal adalah komunikasi antar-perorangan dan bersifat pribadi baik yang terjadi secara langsung (tanpa podium) ataupun tidak langsung (melalui podium). Contohnya kegiatan percakapan tatap muka, percakapan melalui telephone, HP, Internet, teleconference, surat menyurat pribadi. Fokus pengamatannya adalah bentuk-bentuk dan sifat-sifat hubungan (relationship), percakapan, 
interaksi dan karakteristik komunikator. Sedangkan dengan melalui podium yaitu dengan dakwah fardiyah dengan misi pesan-pesan dakwah kepada mad'ü untuk menyeru perbuatan yang makruf dan mencegah perbuatan munkar.

Dari beberapa pendapat di atas, Widjaya menyimpulkan bahwa tujuan komunikasi Interpersonal mempunyai tujuan sebagai berikut:

1. Mengenal diri sendiri dan orang lain.

2. Mengetahui dunia luar.

3. Menciptakan dan memelihara hubungan.

4. Mengubah sikap dan perilaku.

5. Membantu orang lain (Widjaya, 2000: 123).

\section{Teori Komunikasi Interpersonal}

Komunikasi interpersonal merupakan proses yang menggunakan pesan-pesan untuk mencapai kesamaan makna antara dua orang atau lebih dalam sebuah situasi yang memberikan kesempatan yang sama bagi komunikator dan komunikan (Pearson, Nelson, Titsworth, \& Harter, 2003). Proses komunikasi itu ditandai dengan interaksi verbal dan non verbal (De Vito, 2013). Ada beberapa teori yang melandasi proses komunikasi interpersonal, yaitu :

1. Relationship Rules Theory. Teori ini memandang proses komunikasi interpersonal berdasarkan aturan yang berlaku selama proses komunikasi (Shimanoff, 1980). Dengan adanya aturan-aturan ini dapat mengidentifikasi perilaku yang mendukung dan atau merusak komunikasi. Selain itu, aturan-aturan ini dapat digunakan untuk mendeteksi mengapa komunikasi putus dan bagaimana komunikasi itu dapat diperbaiki. Selanjutnya, jika individu mengetahui aturannya, maka individu itu akan lebih mampu menguasai keterampilan sosial yang dibutuhkan dalam komunikasi interpersonal.

2. Relationship Dialectics Theory. Teori ini beranggapan bahwa individu yang terlibat dalam suatu komunikasi interpersonal dapat mengalami ketegangan internal antara sepasang motif yang berlawanan (Rawlins, 1989). Misalnya ketegangan antara sikap closedness dan openness, yaitu konflik antara keinginan untuk berada dalam hubungan tertutup dan keinginan untuk berada dalam suatu hubungan yang terbuka dengan kelompok yang lebih luas. Ketegangan antara autonomy dan connection, yaitu konflik individu yang terjadi karena adanya keinginan untuk tetap menjadi individu yang otonom dan independen tetapi juga adanya keinginan untuk berhubungan dengan orang lain (Sahlstein, 2004). Untuk mengatasi hal tersebut de Vito (2013) memberikan tiga solusi yaitu : 1) individu yang terlibat dalam proses komunikasi interpersonal sebaiknya menerima kekurangan masing-masing, 2) Jika individu ingin terbebas dari tekanan itu, maka individu tersebut bisa keluar dari hubungan itu, 3) Individu perlu menyeimbangkan hidup agar dapat menyegarkan kembali situasi hubungan.

3. Social Penetration Theory. Teori ini menjelaskan proses berkembangnya hubungan dalam komunikasi interpersonal. Hubungan itu, bergerak mulai dari tingkatan yang paling rendah, menuju ke tingkatan yang terdalam, atau ke tingkatan yang lebih bersifat pribadi. Teori ini dimaknai juga sebagai sebuah model yang menunjukkan perkembangan hubungan, yaitu proses individu saling mengenal satu sama lain melalui tahap pengungkapan informasi (Altman \& Taylor, 1973). Dalam proses komunikasi interpersonal membutuhkan kedalaman hubungan, tetapi keluasan informasi juga penting. Dalam beberapa situasi individu bisa sangat terbuka kepada seseorang, tetapi dalam informasi tertentu individu tidak bisa terbuka. Jika suatu hubungan mulai memburuk, maka keluasan dan kedalaman akan berkurang dan disebut depenetrasi. Misalnya, pada saat individu mengakhiri komunikasi 
interpersonal maka informasi akan terpotong, tetapi informasi yang tersisa dapat didiskusikan lebih mendalam.

4. Social exchange Theory. Teori ini mengatakan suatu hubungan interpersonal akan terjadi jika individu menganggap bahwa dengan hubungan tersebut dapat mendatangkan keuntungan (Cook, \& Rice, 2003). Maka dalam hubungan interpersonal terdapat unsur reward, pengorbanan dan keuntungan yang saling mempengaruhi. Hubungan interpersonal dapat dikaji dari keseimbangan antara apa yang diberikan individu dalam hubungan tersebut dengan apa yang dikeluarkan dari hubungan itu. Teori pertukaran sosial ini didasarkan pada teori ekonomi, yang menjelaskan bahwa individu akan memilih sebuah hubungan yang dapat memberikan keuntungan bagi dirinya.

5. Equity Theory. Teori kesetaraan didasarkan pada ide teori pertukaran sosial, tetapi lebih menekankan pada membangun sebuah hubungan antar individu yang didasarkan pada kepentingan yang saling menguntungkan diantara keduanya. Hubungan bisa bertahan jika masing-masing pihak saling memberi dan memperoleh keuntungan yang sepadan. Teori kesetaraan menganggap bahwa individu akan mengembangkan, mempertahankan, dan merasa puas dengan hubungan yang sifatnya adil. Sebaliknya, individu tidak akan berkembang, akan mengakhiri, atau tidak puas dengan hubungan yang tidak adil. Semakin besar ketidakadilan, semakin besar ketidakpuasan dan semakin besar kemungkinan hubungan akan berakhir (De Vito, 2013).

Berdasarkan uraian tersebut, maka dapat disimpulkan bahwa teori-teori itu benar menjelaskan banyak hal tentang mengapa individu mengembangkan hubungan, cara kerja hubungan, cara individu berusaha mempertahankan hubungan, dan alasan mengapa hubungan bisa memuaskan dan tidak memuaskan.

Berdasarkan teori tersebut maka komunikasi interpersonal akan terjalin dengan baik jika mengikuti aturan, ada konflik tetapi pada tahap bisa ditoleransi, luas dan kedalaman informasi meningkat, adanya penghargaan atau keuntungan dari hubungan itu, dan masing-masing individu mendapatkan keadilan dalam hubungan itu. Dalam perpektif sosial budaya proses komunikasi meletakkan kebudayaan sebagai pusat dari proses komunikasi. Oleh karena itu efektifitas komunikasi juga ditentukan oleh pengaruh sosial budaya. Dalam hal ini, termasuk didalamnya adalah aspek kepercayaan atau aspek religi individu yang terlibat dalam komunikasi tersebut. Oleh karen itu artikel ini mengkaji bentuk komunikasi interpersonal dalam kajian islam.

\section{Tujuan Komunikasi Interpersonal}

Tujuan - tujuan komunikasi antarpribadi dapat dilihat dari dua perspektif yaitu: (a) Tujuan tujuan yang dilihat sebagai faktor-faktor motivasi atau sebagai alasan mengapa kita terlibat dalam komunikasi antarpribadi. Dengan demikian komunikasi antarpribadi bias mengubah sikap dan prilaku seseorang. (b) Tujuan - tujuan yang dipandang sebagai hasil efek umum dari komunikasi antarpribadi. Dengan demikian sebagai suatu hasil dari komunikasi antarpribadi adalah kita dapat mengenal diri kita sendiri, membuat hubungan lebih baik, bermakna dan memperoleh pengetahuan tentang dunia luar (Fajar M., 2009).

Menurut Widjaja dalam bukunya Fungsi komunikasi antar pribadi atau komunikasi interpersonal adalah berusaha meningkatkan hubungan insani, menghindari dan mengatasi konflik-konflik pribadi, mengurangi ketidakpastian sesuatu, serta berbagai pengetahuan dan pengalaman dengan orang lain.Komunikasi interpersonal dapat meningkatkan hubungan kemanusiaan diantara pihak-pihak yang berkomunikasi. Dalam hidup bermasyarakat seseorang bisa memperoleh kemudahan dalam hidupnya karena memiliki pasangan hidup. Melalui komunikasi interpersonal juga dapat berusaha membina hubungan baik,sehingga menghindari 
dan mengatasi terjadinya konflik-konflik yang terjadi. Seseorang berkomunikasi dengan orang lain tentu saja mempunyai tujuan tertentu. Adapun tujuan umum yang ingin dicapai dalam komunikasi interpersonal adalah: 1) menyampaikan informasi; 2) berbagi pengalaman; 3) menumbuhkan simpati; 4) melakukan kerja sama; 5) menceritakan kekesalan atau kekecewaan; 6) menumbuhkan motivasi (Purwanto D. 2011).

\section{Urgensi Komunikasi Interpersonal dalam Al-Qur'an}

Komunikasi dalam Islam merupakan proses menyampaikan pesan dengan menggunakan prinsip-prinsip islam dalam pesan maupun metode penyampaiannya. Al-Qur'an menggunakan konsep-konsep seperti balägh, da'wah, basher, nadhár, tadhkirah, dan Mawi'zah untuk mengkomunikasikan pesan Allah kepada manusia. Panduan pertama dan utama adalah alQur'an, mengkomunikasikan prinsip-prinsip dasar Islam dan meletakkan dasar perilaku Islam.

Panduan yang kedua adalah sunnah atau perbuatan, ucapan, dan sifat persetujuan Nabi (SAW), menguraikan dan mengklarifikasi prinsip-prinsip ini dan menghubungkan nya dalam kehidupan nyata manusia (Khalil, 2016).

Walaupun al-Quran secara spesifik tidak menjelaskan komunikasi secara khusus, tetapi ada banyak ayat yang memberikan gambaran umum konsep komunikasi (Kusnadi, 2014). Beberapa kata dalam al-Quran diasumsikan sebagai penjelasan dari bentuk pesan maupun metode komunikasi, yaitu :

1. Qaulan Sadidan, yaitu berbicara yang benar karena menyampaikan pesan yang benar adalah syarat untuk mencapai kebenaran amal (Mubarok \& Andjani, 2014). Hal ini sesuai dengan Firman Alloh dalam Dalam QS An-nisa, ayat 9. Ayat tersebut dapat dimaknai bahwa untuk menegakkan komunikasi yang benar membutuhkan kejujuran. Jujur adalah kesesuaian antara yang diucapkan dengan kejadian yang sebenarnya dan berkata yang benar ketika berhadapan dengan orang yang diharapkan (Mudjib, 2017). Komunikasi yang jujur adalah menyampaikan pesan dengan benar dan berdasarkan fakta dan data. Komunikator tidak boleh mengkomunikasikan informasi yang tidak diketahui secara jelas sumbernya.

2. Qaulan Maysura, yaitu perkataan yang sopan, tidak merendahkan martabat orang lain, tidak menghina, tidak merendahkan kemuliaan orang dan tidak mengungkit segala kebaikan yang pernah diberikan kepada orang lain (Mubarok \& Andjani, 2014). Hal ini dijelaskan dalam Al-Qur'an Q.S Al Isra:28 yang intinya mengajarkan pada seseorang apabila tidak bisa memberi atau mengabulkan permintaan orang lain karena memang tidak ada, maka harus mengatakan dengan perkataan yang baik dan alasan-alasan yang rasional. Pada prinsipnya, qaul maysura adalah segala bentuk perkataan yang baik, lembut, dan melegakan. Komunikator seharusnya menyampaikan informasi dengan bahasa yang mengandung kata-kata yang menyenangkan atau berisi hal-hal yang menggembirakan serta memberikan optimisme bagi individu yang diajak bicara.

3. Qaulan Layyinan, yaitu komunikasi dengan lemah lembut, persuasif, memahami lawan bicara dan mampu mengendalikan emosi (Hefni, 2017). Perkataan yang lembut mencerminkan kepribadian komunikator yang tenang dan mampu mengatasi situasi komunikasi yang terkadang tidak sesuai dengan keinginannya. Qaulan layyina adalah perkataan yang mengandung anjuran, ajakan, pemberian contoh yang dilakukan komunikator dengan meyakinkan komunikan bahwa apa yang disampaikan adalah benar dan rasional, dengan tidak bermaksud merendahkan pendapat atau pandangan orang yang diajak bicara tersebut. Qoulan Layyina dapat ditafsirkan sebagai komunikasi dengan cara yang lunak, tidak memvonis sehingga dapat membuat hati komunikan yang keras menjadi lembut kembali (Hefni, 2017). Dengan qoulan layyina maka sebuah komunikasi bukan 
hanya berdampak pada terserapnya informasi tetapi juga akan berubahnya pandangan, sikap dan perilaku komunikan yang diajak bicara.

4. Qaulan Kariman, yaitu perkataan mulia, mengandung isi, pesan, cara serta tujuannya selalu baik, penuh hormat, mencerminkan akhlak terpuji dan mulia. Dalam hal ini komunikator memilih kata-kata yang mulia, sopan sehingga komunikan merasa bahagia, dihormati dan dimuliakan (Hefni, 2017).

5. Qaulan Ma'rufan, yaitu berkata bijak, berisi ungkapan yang baik, ramah, tidak kasar, tidak menyinggung perasaan, tidak kotor dan tidak menstimulasi komunikan untuk berbuat jahat, berisi pembicaraan yang bermanfaat dan menimbulkan kebaikan (Hefni, 2017). Secara harfiah ma'rufa adalah baik dan diterima oleh nilai-nilai yang berlaku di masyarakat. Ucapan yang baik adalah ucapan yang diterima sebagai sesuatu yang baik dalam pandangan masyarakat lingkungan penutur.

6. Qaulan Baligha, yaitu perkataan yang jelas maknanya, terang, dan tepat mengungkapkan apa yang dikehendaki (Mubarok \& Andjani, 2014). Baligha mengandung unsur utama, yaitu bahasanya tepat, sesuai dengan yang dikehendaki, dan isi perkataan adalah suatu kebenaran (Islami, 2013). Komunikasi akan efektif jika komunikator menggunakan kata-kata yang sederhana, tepat sasaran, komunikatif, mudah dimengerti, langsung ke pokok masalah, dan tidak berbelitbelit. Agar komunikasi tepat sasaran, maka gaya bicara dan pesan yang disampaikan hendaklah disesuaikan dengan masa perkembangan komunikan. Dengan demikian pesan disebut balighan, apabila : 1) seluruh pesan tertampung dalam kalimat yang disampaikan, 2) kalimatnya tidak berteletele, tetapi tidak pula terlalu singkat sehingga mengaburkan pesan, 3) Kosa kata yang disampaikan tidak asing bagi komunikan, 4) Kandungan gaya bahasa sesuai dengan sikap komunikan, dan 5) Menggunakan tata bahasa yang baik. Berdasarkan uraian tersebut maka dapat disimpulkan bahwa aspek-aspek komunikasi interpersonal dalam islam dapat dilihat dalam tabel berikut:

Daftar tabel Komunikasi Interpersonal dalam Al-Qur'an

\begin{tabular}{|c|c|c|c|}
\hline No. & Aspek & Indikator & Sumber Al-Qur'an \\
\hline 1. & Qoulan Sadida & $\begin{array}{l}\text { - Menyampaikan } \\
\text { informasi yang } \\
\text { benar dan } \\
\text { berdasarkan fakta } \\
\text { dan data } \\
\text { - Menyampaikan } \\
\text { informasi berdasar } \\
\text { sumber yang jelas }\end{array}$ & QS. An Nisa: 9 \\
\hline 2. & Qoulan Masysura & $\begin{array}{l}\text { - } \begin{array}{l}\text { Berkomunikasi } \\
\text { dengan bahasa yang } \\
\text { mudah dimengerti }\end{array} \\
\text { - Menggunakan } \\
\text { kalimat yang } \\
\text { menyenangkan } \\
\text { - Menyampaikan } \\
\text { informasi yang }\end{array}$ & QS. Al Isra' : 28 \\
\hline
\end{tabular}




\begin{tabular}{|c|c|c|c|}
\hline & & $\begin{array}{l}\text { berisi informasi } \\
\text { yang } \\
\text { menggembirakan } \\
\text { - Menyampaikan } \\
\text { informasi yang } \\
\text { memberikan } \\
\text { optimisme bagi } \\
\text { pembaca yang di } \\
\text { ajak bicara }\end{array}$ & \\
\hline 3. & Qoulan Layyina & 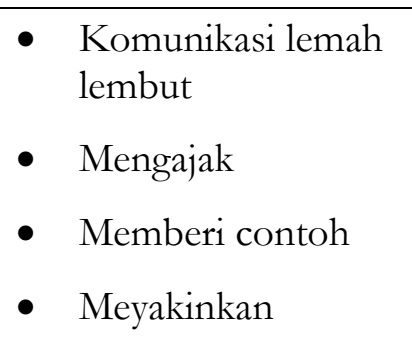 & QS. Thoha: 44 \\
\hline 4. & Qoulan Karima & $\begin{array}{l}\text { - } \text { Berkata santun } \\
\text { - Tanpa kalimat yang } \\
\text { kasar }\end{array}$ & QS. Al Isra' : 23 \\
\hline 5. & Qoulan Ma'rufa & $\begin{array}{l}\text { - } \text { Berkata baik } \\
\text { - } \text { Menggunakan } \\
\text { ungkapan yang baik } \\
\text { - } \text { Ramah } \\
\text { - } \text { Tidak menyinggung } \\
\text { perasaan } \\
\text { - } \quad \begin{array}{l}\text { Berbicara yang } \\
\text { bermanfaat }\end{array}\end{array}$ & QS. An Nisa : 8 \\
\hline 6. & Qoulan Baligha & $\begin{array}{l}\text { - } \begin{array}{l}\text { Menggunakan kata- } \\
\text { kata sederhana }\end{array} \\
\text { - Bahasa mudah } \\
\text { dimengerti } \\
\text { - Bicara tidak berbelit } \\
\text { belit }\end{array}$ & QS. An Nisa : 63 \\
\hline
\end{tabular}

\section{Implementasi Komunikasi Interpersonal Pustakawan Persfektif Al-Qur'an}

Implementasi komunikasi interpersonal untuk pustakawan dalam persfektif Al-Qur'an, ada beberapa hal yang dapat di jadikan model, diantaranya :

1. Komunikator/Pustakawan melakukan penyandian (encoding) untuk menyampaikan pesan dalam bentuk lambang atau aktifitas kepustakaan.

2. Pesan tersebut disalurkan ke komunikan bisa melalui media. Pada saat proses menyampaikan tersebut, sering ada gangguan, baik gangguan lingkungan, psikologis maupun gangguan semantik. Gangguan inilah yang menyebabkan pesan tidak 
tersampaikan dengan baik ke komunikan. Oleh karena itu selama proses menyampaikan pesan perlu di masukkan metode komunikasi yang islami, yaitu sadidan, maysura, layyinan, kariman, ma'rufa dan baligha. Misalnya, saat menyampaikan pesan komunikator harus menggunakan qaulan sadidan dan qaulan baligha, yaitu berkata yang jujur dan menggunakan kata-kata yang jelas. Artinya komunikator/pustakawan harus menyampaikan informasi yang jelas sumbernya dan menggunakan bahasa yang mudah dimengerti, sehingga mengurangi gangguan psikologis maupun gangguan semantik. Dengan demikian pesan akan tersampaikan dengan benar ke komunikan/pembaca. Proses komunikasi yang baik juga harus menggunakan qaulan maysura, qaulan layyinan, qaulan karima dan qaulan ma'rufa yaitu menggunakan kata-kata yang lembut, sopan, menyenangkan atau berisi hal-hal yang menggembirakan serta memberikan optimisme bagi komunikan/pembaca. Dengan metode ini maka gangguan psikologis bisa teratasi, karena komunikan merasa nyaman menerima pesan dari komunikator/pustakawan.

3. Komunikan menafsirkan (decoding) pesan hingga mempunyai makna. Komunikan memberi tanggapan terhadap pesan yang diberikan oleh komunikator sehingga komunikator dapat menganalisis pesan yang disampaikan sudah sesuai dengan tujuan atau belum

Demikianlah, proses komunikasi interpersonal yang islami akan mengurangi terjadinya gangguan yang dapat menghambat tersampaikannya pesan ke komunikan

\section{PENUTUP}

Sebagai Pustakawan mengimplementasikan bentuk komunikasi interpersonal dalam persfektif komunikasi islam (Al-Qur'an) merupakan hal yang di anjurkan, dikarenakan teori komunikasi yang berasal dari teori barat lebih menekankan pada bentuk komunikasi intrapersonal, komunikasi kelompok, dan komunikasi organisasi. Komunikasi islam melengkapi bentuk komunikasi tersebut dengan metakomunikasi yaitu komunikasi dengan Alloh SWT. Integrasi konsep komunikasi interpersonal islami ke dalam konsep barat memberikan efek/dampak mengurangi gangguan psikologis dan semantik dalam proses komunikasi. Pesan yang terkirim ke komunikan menjadi lebih mengena karena saluran/media yang digunakan cenderung rendah tingkat gangguannya. Tugas pustakawan akan lebih memberikan kesan positif terhadap pembaca dengan menerapkan komunikasi dalam Al-Qur'an yaitu dengan berkata secara : Qaulan Sadidan, Qaulan Maysura, Qaulan Layyinan, Qaulan Kariman, Qaulan Ma'rufa dan Qaulan Baligha.

\section{DAFTAR PUSTAKA}

Altman and Taylor. (1973). Social Penetration: The Development of Interpersonal Relationship. New York : Rinehart \& Winsto

Ayish, M., I., (2003), Beyond Western- Oriented Communication Theories: A Normative Arab Islamic Perspective, Journal of the European Institute for Communication and Culture, 10 (2)79 -92

Cook, K.S and Rice, E., (2003), Handbook of Social Psychology, edited by John Delamater. New York: Kluwer Academic/Plenum Publishers

De Vito, J., (2013). The Interpersonal Communication Book. 13th edition, United States: Pearson Education Faruqi.I.R., (1984). Dakwah Islam dan Misi Kristen Sebuah Dialog Internasional. Ahmad Von Denffer dan Emilio Castro, eds., terj. Ahmad Noer Z. Bandung: Risalah

Fajar, M. Ilmu Komunikasi Teori dan Praktek Edisi Pertama. Yogyakarta: Graha Ilmu, 2009) 
Hefni, H., (2017), Komunikasi Islam, Jakarta : Prenadamedia Group Islami, D.I, (2013), Konsep Komunikasi Islam Dalam Sudut Pandang Formula Komunikasi Efektif, Wacana, XII (1), 41-66

Kazim, S., (2013) The Concept of Communication in Islam, Sayedee's Conviction: A Travesty of Justice. L (51).

Khalil, A.I.A.E., (2016), The Islamic Perspective of Interpersonal Communication, Journal of Islamic Studies and Culture, 4, (2), 22-37.

Kotler, P., (2000), Marketing Management. New Jersey : Prentice Hall Intl.

Kusnadi, (2014), Komunikasi dalam al-Qur'an (Studi Analisis Komunikasi Interpersonal pada Kisah Ibrahim), Intizar, 20 (2), 267-284

Mubarok \& Adjani, M.D., (2014), Komunikasi Antarpribadi Dalam Masyarakat Majemuk, Jakarta : Dapur Buku

Mujib,A., (2017), Teori Kepribadian, Perpektif Psikologi Islam, Jakarta : PT. Rajagrafindo Persada.

Mulyana, D., (2011), Ilmu Komunikasi, Suatu Pengantar, Bandung: Remaja Rosda Karya. Pearson, J. C.. Nelson, P.E., Titsworth, S., Harter, L., (2003), Human Communication, New york: The McGraw-Hill Companies

Purwanto, D. Komunikasi Bisnis Edisi Keempat. (Jakarta: Erlangga, 2011)

Rawlins, W. K. (1989). A dialectical analysis of the tensions, functions, and strategic challenges of communication in young adult friendships. In Communication yearbook 12, (pp. 157-189), J. A. Andersen (ed.), Thousand Oaks, CA: Sage.

Sahlstein, E.M. (2004). Relating at a Distance: Negotiating being Together and being Apart in LongDistance Relationships. Journal of Social \& Personal Relationships, 21, 689-710

Shimanoff, S. B. (1980). Communication rules: Theory and research. California: Sage Publication

Suhaimi, (2012), Dakwah and Communication Programmes in Tertiary Higher Education in Indonesia: A Brief Survey, Islamiyyat, 34, 145 - 149

Suryani, W., (2015), Komunikasi Transedental Manusia-Tuhan, Farabi, 12 (1), 150-163 